University of Nebraska - Lincoln

DigitalCommons@University of Nebraska - Lincoln

Sociology Department, Faculty Publications

Sociology, Department of

$1-2010$

\title{
Self injurious behavior among homeless young adults: A social stress analysis
}

\author{
Kimberly A. Tyler \\ University of Nebraska-Lincoln, kim@ktresearch.net \\ Lisa A. Melander \\ University of Nebraska-Lincoln, Imeland@ksu.edu \\ Elbert P. Almazan \\ Central Michigan University, almaz1ep@cmich.edu
}

Follow this and additional works at: https://digitalcommons.unl.edu/sociologyfacpub

Part of the Sociology Commons

Tyler, Kimberly A.; Melander, Lisa A.; and Almazan, Elbert P., "Self injurious behavior among homeless young adults: A social stress analysis" (2010). Sociology Department, Faculty Publications. 76.

https://digitalcommons.unl.edu/sociologyfacpub/76

This Article is brought to you for free and open access by the Sociology, Department of at DigitalCommons@University of Nebraska - Lincoln. It has been accepted for inclusion in Sociology Department, Faculty Publications by an authorized administrator of DigitalCommons@University of Nebraska - Lincoln. 


\title{
Self injurious behavior among homeless young adults: A social stress analysis
}

\author{
Kimberly Tyler, ${ }^{1}$ Lisa Melander, ${ }^{1}$ and Elbert Almazan ${ }^{2}$ \\ ${ }^{1}$ University of Nebraska-Lincoln \\ ${ }^{2}$ Central Michigan University \\ Corresponding author - Kimberly Tyler, Department of Sociology, University of Nebraska-Lincoln, \\ 717 Oldfather Hall, Lincoln, NE, USA; tel 402 472-6073, email kim@ktresearch.net
}

\begin{abstract}
Although self-mutilation has been studied from medical and individual perspectives, it has rarely been examined within a social stress context. As such, we use a social stress framework to examine risk factors for self-mutilation to determine whether status strains that are often associated with poorer health outcomes in the general population are also associated with self-mutilation among a sample of young adults in the United States who have a history of homelessness. Data are drawn from the Homeless Young Adult Project which involved interviews with 199 young adults in 3 Midwestern United States cities. The results of our path analyses revealed that numerous stressors including running away, substance use, sexual victimization, and illegal subsistence strategies were associated with more self-mutilation. In addition, we found that certain social statuses exacerbate the risk for self-mutilation beyond the respondents' current situation of homelessness. We discuss the implications of our findings for the social stress framework and offer suggestions for studying this unique population within this context.
\end{abstract}

Keywords: USA, social stress, homeless, young adults, self-mutilation

\section{Introduction}

Self injury refers to the act of deliberately harming oneself, causing minor to moderate injuries without suicidal intent (Favazza, 1998; Suyemoto, 1998) and includes a variety of behaviors such as cutting, stabbing, burning, and scratching the skin (Favazza and Conterio, 1989; Ross and Heath, 2002). Although the actual prevalence of self injury is unknown (Nock, Wedig, Janis, \& Deliberto, 2008), percentages in the general population vary considerably with rates of $4 \%$ for adults (Briere \& Gil, 1998), 17$38 \%$ among college students (Gratz et al., 2002; Whitlock et al., 2006), and 69\% among high-risk youth (Tyler et al., 2003). Estimates for psychiatric inpatients range from 21\% (Briere \& Gil, 1998 ) to $82 \%$ (Nock \& Prinstein, 2004). Often referred to as selfmutilation, self injury is a major health issue that can affect people of all ages, gender, or racial/ethnic groups and is believed to be increasing in prevalence among adolescents and youth (Ross \& Heath, 2002).

Although macro-level processes such as differential access to and possession of wealth, power, and prestige may exacerbate the risk for poor mental health outcomes such as self injury, this behavior has rarely been examined within a social stress perspective. Within this context, stress exposure heightens an in- dividual's risk of experiencing mental health problems such as self-mutilation. This is particularly relevant for homeless young adults because these individuals experience numerous stressors but often lack the personal resources such as family support that may buffer them from the negative effects of stress. In this paper we use a social stress framework (Aneshensel, 1999; Wheaton, 1999) to examine our research questions: Do certain stigmatized statuses exacerbate the risk of self-mutilation beyond the social circumstance of ever being homeless? Are the correlates of selfmutilation among homeless young adults different from those found among general population or clinical samples? Although homeless young people experience numerous stressors due to the daily survival issues that they typically face (e.g., finding food and a place to sleep), it is possible that additional status strains such as gender and sexual orientation, which are often found to be associated with poorer health outcomes (Biernbaum and Ruscio, 2004; Van Voorhees et al., 2008) further increase the risk for self-injury.

\section{A social stress framework}

A social stress framework, which guides the current study, is useful for understanding the process that links numerous stress- 
ors experienced by many homeless young people with self injurious behaviors. Stressors, according to Wheaton, are "conditions of threats, demands or structural constraints that by their very occurrence or existence, call into question the operating integrity of the organism" (1999, p. 177). Wheaton states that it is important to measure a variety of stressors to avoid underestimating their impact, recognizing that stressors are linked to each other and may have direct or indirect effects on mental health. Although the majority of people in the general population adapt to stress, those with unique social circumstances such as homeless individuals may engage in more harmful behavior compared to those in the general population due to the additional stressors associated with their social situation.

The location of individuals within the social system influences their chances of encountering stressors, increasing the likelihood of them becoming emotionally distraught (Aneshensel, 1992). In other words, stressors tend to vary according to one's position in society and thus their impact on mental health outcomes, such as self-mutilation, are likely to differ across groups and/or social conditions. There is a large body of research that finds for example that social status is a correlate of both physical and/or mental health among adults (Demakakos et al., 2008; Honjo et al., 2006; Kubzansky et al., 1998). Among homeless individuals, those who are faced with the stressors associated with their disadvantaged circumstance may engage in destructive behaviors including self-mutilation because they lack adaptive alternatives. The daily struggles that homeless individuals experience such as having to secure a place to stay for the night and finding food makes the situation of homelessness a unique social circumstance. Additionally, macro-level factors such as perceived or experienced discrimination and micro-level factors such as growing up in an abusive household may encourage some homeless individuals to self injure as a means of reducing stress and relieving tension. To the extent that homeless young adults have little control over their sources of stress, self-mutilation may become more likely among this group.

Status strain, which is a type of stressor, occurs when majority and minority groups have differential access and possession of power, prestige, and resources that ameliorate or exacerbate the risk for mental health outcomes such as self-mutilation (Pearlin, 1999). Gender and sexual orientation are status strains that may be important in understanding the prevalence of selfmutilation. For example, among homeless youth, females experience unique stressors including higher rates of sexual victimization than males (Tyler et al., 2001) and this is associated with higher levels of depression (Whitbeck et al., 2000). Sexual minorities are often stigmatized (D'Augelli, 1998) because of their social status and experience numerous negative outcomes including victimization (D'Augelli et al., 2002) and have poor physical and/ or mental health (Clatts and Davis, 1999; Cochran et al., 2003; Kipke et al., 1995; Ueno, 2005). Additionally, because homeless females and sexual minority youth generally experience more sexual abuse (Cochran et al., 2002; Tyler, 2008; Tyler and Cauce, 2002) and abuse is associated with self-mutilation (Briere and Gil, 1998; Gladstone et al., 2004; Lipschitz et al., 1999), these individuals may engage in higher rates of self injurious behaviors. In sum, homelessness, gender, and sexual orientation are markers of social placement (Aneshensel et al., 1991) that affect the way in which lived reality is experienced, impacting both the stressors encountered as well as the mechanisms mobilized to deal with stress.

\section{Factors associated with self-mutilation}

Researchers focusing on self-mutilation have examined gender and sexual orientation among a variety of populations in- cluding clinical, community, and high-risk individuals (e.g., homeless and runaway youth). Studies focused on gender have found mixed results. For example, some researchers have found that females are significantly more likely to self-mutilate compared to males (Lipschitz et al., 1999; Ross and Heath, 2002; Zlotnick et al., 1999) whereas other researchers report no gender differences (Briere and Gil, 1998; Gratz et al., 2002). Although there is a dearth of studies on sexual orientation and self injury, those that exist show that gay, lesbian, and bisexuals (GLBs) are at greater risk for self injurious behavior compared to their heterosexual counterparts (Skegg et al., 2003; Whitlock et al., 2006).

Experiences within the family of origin as well as mental health factors are also associated with self-mutilation. Studies including both clinical and non-clinical populations generally find a higher risk of self-mutilation among those with a history of physical and/or sexual abuse (Briere and Gil, 1998; Gladstone et al., 2004; Lipschitz et al., 1999; Tyler et al., 2003). Although fewer studies have examined neglect, some researchers also find this to be a strong correlate of self-mutilation (van der Kolk et al., 1991; Lipschitz et al., 1999). In addition to maltreatment, other risk factors for self-mutilation among clinical samples include depression, post traumatic stress disorder (PTSD), victimization, and/or substance abuse (Gladstone et al., 2004; Swift et al., 1996; Zlotnick et al., 1999). Depression is also found to be a precursor to self-mutilation among general and high-risk population samples (Ross and Heath, 2002; Tyler et al., 2003).

Homeless individuals not only have to agonize over daily survival but are also shunned within society because they do not live up to cultural norms and expectations. These individuals lack conventional housing, employment, family ties, and other stable relationships and often do not receive appropriate physical and mental health treatment, possibly because many homeless youth mistrust mainstream institutions (Auerswald \& Eyre, 2002). They also engage in risky lifestyles through their participation in delinquent activities and running away, both of which place homeless youth at increased risk for negative health outcomes (Chen et al., 2004; Tyler et al., 2003). As such, they live on the outskirts of society and are often ostracized and blamed for their current social circumstance. Due to their lack of resources and support, numerous homeless individuals may cope with distal and proximal stressors such as child maltreatment histories and victimization in maladaptive ways such as through self-mutilation. In other words, self-mutilation may help the individual cope because it is a way to express and regulate overwhelming or intolerable emotions by creating a sense of control (Suyemoto, 1998). This is a timely issue given the current economic instability in the U.S. which may lead to increases in homelessness among this young population. Additionally, declining economic conditions could potentially lead to even higher distress among those who are currently homeless, resulting in even poorer mental health.

Although self injury has generally been overlooked in studies of homeless young adults, this group is especially at high-risk for this damaging behavior for several reasons. First, the majority of homeless young people have experienced child maltreatment (Tyler \& Cauce, 2002), which is a major risk factor for self-mutilation. Second, homeless young people in general engage in high-risk behaviors such as frequently running away from home and delinquency (Chen et al., 2004; Tyler et al., 2001, 2003) and experience numerous mental health problems including depression, PTSD, and substance abuse (Slesnick and Prestopnik, 2005; Tyler et al., 2003; Whitbeck et al., 2000), all of which are risk factors for self injury. Third, many homeless young adults lack resources and adequate support (Tyler, 2008); therefore, they may be less willing to ask for help when problems arise. As such, using a path model 
that is derived from a social stress framework and literature on both self-mutilation and homelessness, we examine whether gender and sexual orientation, both of which are status strains, exacerbate the risk for self-mutilation beyond the social circumstance of being homeless. If, however, we find no differences by gender and sexual orientation, we would conclude that homelessness by itself is such a unique circumstance that these status strains do not necessarily add to their already elevated levels of stress. On the other hand, if rates of self injury differ by gender and sexual orientation, we would conclude that these are additional strains that further increase the risk for self-mutilation beyond being homeless.

\section{Data and methods}

Data are from the Homeless Young Adult Project (HYAP), a pilot study designed to examine the effect of neglect and abuse histories on homeless young adults' mental health and high-risk behaviors. Over a period of approximately one year (from April of 2004 through June of 2005), 199 young adults were interviewed in three Midwestern United States cities. Of this total, 144 were homeless and 55 were currently housed. Homeless was defined as those currently residing in a shelter, on the street, or living independently (e.g., with friends) because they had run away, been pushed out, or drifted out of their family of origin. Study eligibility for this portion of the sample required young people to be between the ages of 19 and 26 and homeless. The currently housed individuals were recruited via peer nominations from the homeless respondents. Despite being housed at the time of the interview, 28 out of the 55 housed young adults had extensive histories of being homeless and had run away from home numerous times (27 young adults had never been homeless and were omitted from the present analyses). In fact, the 28 housed young adults with run away histories reported running away more times than the homeless individuals (Mean $=5.72$ vs. 4.99 ). What differentiated these two groups was their housing status at the time of the interview, indicating that homelessness is a situation that is very fluid and not easily defined (Wright, 1991). The final sample used for this research included 172 young adults who were homeless or had a history of running away and being homeless.

The interviewers included individuals who have worked on past projects dealing with at-risk individuals, have served for several years in agencies and shelters that support homeless young people, and are very familiar with local street cultures. Additionally, all interviewers completed the Collaborative Institutional Review Board Training Initiative course for the protection of human subjects in research. Interviewers approached shelter residents and located eligible respondents in areas where street people congregate. The sampling protocol included varying the times of the day on both weekdays and weekends that interviewers went to these locations. This systematic sampling strategy maximized locating homeless young adults was used because it is well established that it is not possible to randomly sample homeless populations (Wright et al., 1995). Interviewers obtained informed consent from young adults prior to participation, told them about the confidentiality of the study, and informed them that their participation was voluntary. The interviews, which were conducted in shelter interview rooms or quiet corners of fast food restaurants or coffee shops, lasted approximately one hour and all participants received \$25 for their involvement. Referrals for shelter, counseling services, and food services were offered to the young adults at the time of the interview. Although interviewers did not formally tally screening rates, they reported that very few young adults refused to participate. The Institutional Review Board at the University of Nebraska-Lincoln approved this study.
Measures

Because stressors tend to vary according to one's social location and their impact on mental health outcomes is likely to differ across groups or social conditions, we examine gender and sexual orientation, which are status strains that are important for understanding self injury. Gender was coded $0=$ male and $1=$ female, and sexual orientation was coded $0=$ GLB and $1=$ heterosexual. The following measures, which demonstrate excellent reliability (cf. [Tyler et al., 2001; Whitbeck and Simons, 1990), have been used extensively with homeless populations to explain mental health outcomes and high-risk behaviors.

Sexual abuse was measured using seven items adapted from previous research with homeless youth (Whitbeck \& Simons, 1990; alpha reliability for this scale $=.93$ ). For example, respondents were asked how often an adult or someone at least 5 years older had done the following things to them before they were on their own and while they were under the age of 18: asked you to do something sexual, had you touch them sexually, and put or tried to put anything or any part of their body into you sexually. Response categories ranged from $0=$ never to $7=$ more than once a day. Due to skew, each item was dichotomized $(0=$ never and $1=$ at least once $)$ and then summed so a higher score indicated more sexual abuse. Cronbach's alpha was .88 .

Neglect was comprised of five items from a supplementary scale within the Parent-Child Conflict Tactics Scale (Straus et al., 1998). For example, respondents were asked how many times their caretaker left them home alone when someone should have been with them. Response categories ranged from $0=n e v e r$ to $7=$ more than once $a$ day. A mean scale was created so that a higher score indicated more neglect. The alpha reliability was .83 .

Number of times run was a single item indicator that measured the total number of times the young people had run away from home. Due to skew, this variable was collapsed into $1=$ ran away once, $2=$ ran away 2 or 3 times, $3=$ ran away 4 or 5 times, $4=$ ran away $6-10$ times, $5=$ ran away $11-20$ times, and $6=$ ran away more than 20 times.

PTSD was comprised of 15 items from the Impact of Event Scale (Horowitz et al., 1979) which was designed to measure subjective distress in response to any stressful or traumatic life events. These subscales have high internal consistency and good predictive validity (Briere, 1997). Respondents were asked to indicate how frequently statements such as, "I thought about it when I didn't mean to" and "I tried to remove it from my memory" were true for them in the past seven days in reference to a stressful or traumatic life event. Response categories included $0=$ not at all, $1=$ rarely, $3=$ sometimes, and $5=$ often, with higher scores indicating more stressful impact. A summed scale was created so that a higher score indicated higher levels of PTSD. The suggested cut-off point is 26 , above which a moderate to severe impact is indicated. All items loaded on a single factor with an alpha reliability of .95 .

Substance use was measured by combining 12 individual variables that asked respondents how often they had drunk beer, wine or liquor, used marijuana, or used crank, amphetamines, cocaine, opiates, hallucinogens, barbiturates, inhalants, or designer drugs in the past year. Alpha reliability was .79. The items were coded such that a score of $0=$ the respondent had not drunk any form of alcohol, did not use marijuana, or any type of illicit drugs in the past year, $1=$ the young adult drank alcohol but had not engaged in any of the other types of substance use, $2=$ the individual had used both alcohol and marijuana or just marijuana but not illicit drugs, and $3=$ that the respondent had used illicit drugs regardless of their alcohol or marijuana use. 
Sexual victimization consisted of four items that focused on the frequency with which respondents had unwanted sexual experiences since being on their own. Items included for example having been forced to do something sexual and having been sexually assaulted and/or raped. Responses ranged from $0=$ never to $3=$ many times. Each of the individual items were dichotomized due to skew and then summed with a higher score indicating more sexual victimization. Cronbach's alpha was .83.

Illegal subsistence strategies was measured using 14 items that asked respondents, for example, how often they had stolen clothes from stores, broken into a house, store, or school, or beaten someone up. Due to skew, the 14 items were dichotomized $(0=$ never and $1=$ at least once $)$ and then summed such that a higher score indicated engaging in more illegal subsistence strategies. Cronbach's alpha was .86.

The dependent variable, non-suicidal self injurious behavior, was measured using the Deliberate Self-Harm Inventory (Gratz, 2001). Respondents were asked if they had ever engaged in a series of 16 types of intentional self injury without intending to kill themselves (see Table 1). A summed scale was created with higher scores indicating more self injurious behavior. Cronbach's alpha was .84.

\section{Data analytic strategy}

In order to address our first research question, we use t-tests to generate mean comparisons between males and females and between heterosexuals and GLBs to assess whether gender and sexual orientation exacerbate the risk for self-mutilation among homeless youth. Next, to address our second research question of whether the correlates of self-mutilation among homeless young adults differ from those found among general population or clinical samples, we hypothesize a fully recursive path model using variables from past research that have been found to be significantly associated with self-mutilation among clinical and community samples.

\section{Results}

\section{Sample characteristics}

The sample included 69 females (40.1\%) and 103 males (59.9\%). Of these, 35 respondents (20.3\%) self-identified as GLB (14 males and 21 females). The age of the sample ranged from
19 to 26 years with a mean of 21.45 years. Forty-eight percent of the sample had received a high school diploma and the majority of the sample was white $(80 \%)$. Almost half of the sample (47\%) had experienced sexual abuse and $78 \%$ had experienced neglect. The majority of respondents had run from home 1 time $(46 \%)$ but $22 \%$ had run 2 or 3 times and $32 \%$ had run 4 or more times. Sixty-one percent of young adults were above the cut off for moderate or severe PTSD, and 39\% of respondents have been sexually victimized on the street at least once. Numerous young adults (40\%) reported using illicit drugs in the past year, and almost one-half of respondents $(49 \%)$ had engaged in 3 or more illegal subsistence strategies since leaving home. Overall, $63 \%$ (109) of young adults have ever self-mutilated. Of these, $77 \%$ have done so more than once $($ Median $=8)$.

\section{Individual self-mutilation items}

\section{Gender}

Sixty-two percent of males and $66 \%$ of females have ever selfmutilated, and of these, $49 \%$ of males and $55 \%$ of females have done so more than once. Although females are more likely to self-mutilate and do so multiple times compared to males, this difference was not statistically significant (results not shown). A list of the individual self-mutilation items for the total sample and for males and females are presented in the first three columns of Table 1. Consistent with the literature, cutting of the skin is the most common form of self-mutilation (Favazza and Conterio, 1989; Ross and Heath, 2002) among both females (51\%) and males (31\%). Other frequently reported types of self injury included severely scratching themselves (32\% for females, $19 \%$ for males) and intentionally burning themselves with a lighter or match ( $23 \%$ for females, $28 \%$ for males).

\section{Sexual orientation}

Sixty percent of heterosexual young adults have ever selfmutilated compared to $80 \%$ of sexual minority young people. Of those who have self-mutilated, $93 \%$ of GLB young adults have done so more than once compared to $72 \%$ of heterosexual respondents. GLB young adults were significantly more likely to self-mutilate and to do so multiple times compared to heterosexual young adults, which is consistent with our expectation (results not shown). A list of the individual self-mutilation items for heterosexuals and sexual minorities are presented in the last two columns of Table 1. The two most commonly reported types

Table 1. Individual self-mutilation items by gender and sexual orientation.

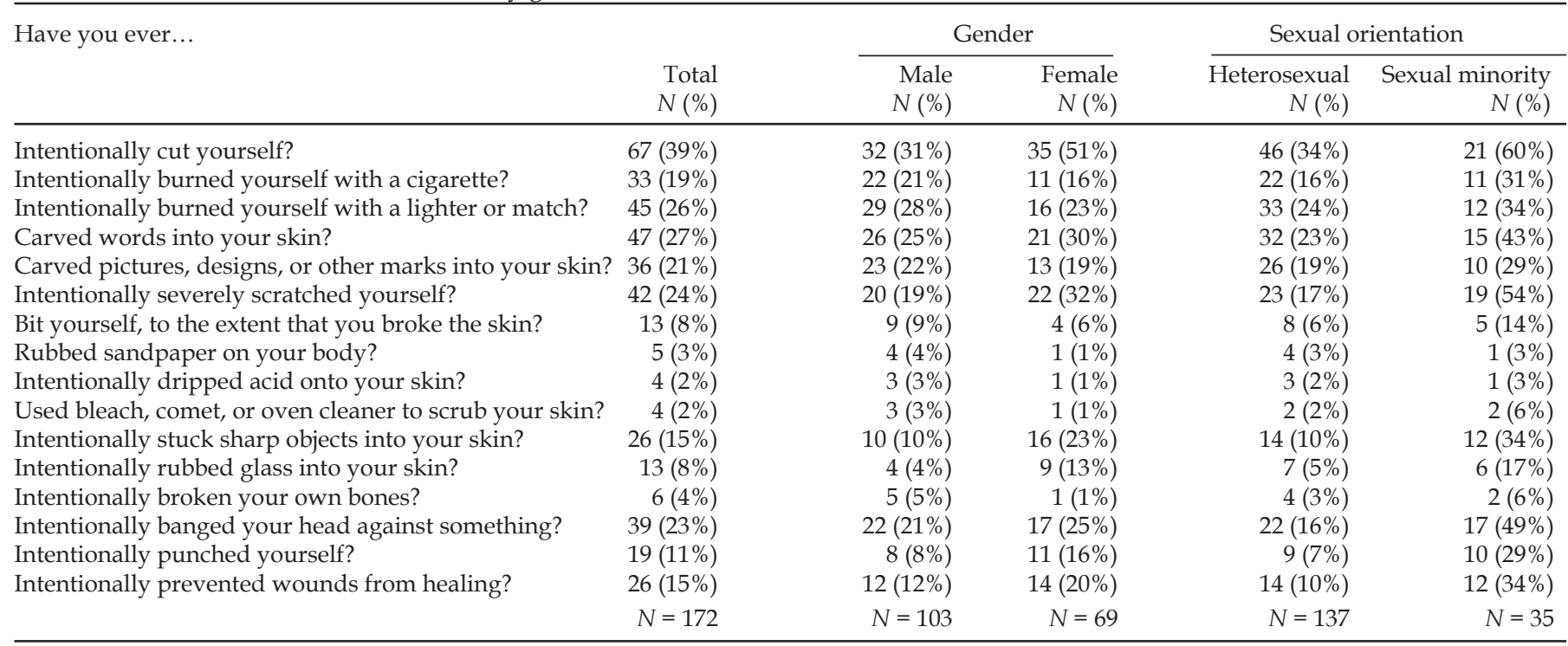


of self-mutilation among GLBs included intentionally cutting themselves (60\%) and severely scratching themselves (54\%) and for heterosexuals it was intentionally cutting (34\%) and intentionally burning themselves with a lighter or match $(24 \%)$.

\section{Mean comparisons}

\section{Gender}

Mean comparisons for all study variables for homeless young adult males versus females and GLBs compared to heterosexuals are shown in Table 2. Consistent with a social stress framework, females experience more stressors compared to their male counterparts. For example, females were significantly more likely to have experienced more sexual abuse $(t=-3.18 ; p<.01)$, to have run away from home more often $(t=-2.53 ; p<.05)$, and to have experienced more sexual victimization compared to males $(t=-5.12 ; p<.001)$. However, there was no significant difference in the mean for self-mutilation between males and females.

\section{Sexual Orientation}

GLB young adults were significantly more likely to have experienced more sexual abuse $(t=4.81 ; p<.001)$, higher levels of $\operatorname{PTSD}(t=4.27 ; p<.001)$, and more sexual victimization $(t=4.99$; $p<.001)$ compared to heterosexual young adults. Additionally, GLBs were more likely to have run away from home more often $(t=2.45 ; p<.05)$ and engage in more illegal subsistence strategies $(t=2.21 ; p<.05)$ compared to their heterosexual counterparts. It appears that because of status strain, GLB young adults experience a greater number of stressors compared to heterosexuals, which is likely to result in poorer mental health. This is supported by our mean comparison test which shows that GLB young adults experience significantly more self-mutilation compared to their heterosexual counterparts $(t=4.58 ; p<.001)$.

\section{Multivariate results}

In order to explore the numerous stressors that are associated with self-mutilation, we estimated a fully recursive path model using the maximum likelihood (ML) procedure in Mplus 5 (Muthén \& Muthén, 1998-2007). The statistical assumptions of ML estimation (e.g., multivariate normality of the endogenous variables) were satisfied. This model takes into account both the direct effects of different stressors on self-mutilation as well as their indirect effects through substance use, sexual victimization, and illegal subsistence strategies (see Figure 1). Results for the path analysis in Figure 1 revealed that females $(\beta=.13)$ and those experiencing higher levels of neglect $(\beta=.17)$ were likely to report running away from home more often. GLB young adults and those who experienced a higher level of neglect reported more PTSD $(\beta=-.28 ; \beta=.17$, respectively).
Higher levels of substance use were associated with being male $(\beta=-.24)$ and experiencing higher levels of neglect $(\beta=.23)$. Approximately $14 \%$ of the variance in substance use was explained by these variables. Experiencing more sexual victimization was associated with being female $(\beta=.28)$ and GLB $(\beta=-.18)$. Additionally, experiencing more sexual abuse $(\beta=.18)$, neglect $(\beta=.15)$, and PTSD $(\beta=.17)$ were related to higher levels of sexual victimization. These variables explained approximately $32 \%$ of the variance in sexual victimization. Illegal subsistence strategies were associated with being male $(\beta=-.15)$ and more frequent running away $(\beta=.21)$, PTSD $(\beta=.22)$, and neglect $(\beta=.18)$. Approximately $22 \%$ of the variance in illegal subsistence strategies was explained by these variables. Finally, being GLB $(\beta=-.16)$ and more frequent running away $(\beta=.14)$, substance use $(\beta=.17)$, sexual victimization $(\beta=.18)$, and illegal subsistence strategies $(\beta=.17)$ were associated with more selfmutilation. These variables explained approximately $36 \%$ of the variance in self-mutilation. Although these findings are generally supportive of our expectations, gender was not significantly associated with self-mutilation.

\section{Indirect effects}

Four variables had a significant indirect effect on self-mutilation. In addition to the direct effect, sexual orientation also had a significant indirect effect on self-mutilation through sexual victimization. Specifically, GLBs had significantly higher levels of sexual victimization which, in turn, was positively associated with self-mutilation. Sexual abuse also had a significant indirect effect on self-mutilation. That is, sexually abused respondents had significantly higher levels of sexual victimization which, in turn, was positively correlated with self-mutilation. Additionally, neglected individuals had significantly more substance use which was positively associated with self-mutilation. Finally, PTSD had a significant indirect effect on self-mutilation through two avenues. Those with higher levels of PTSD engaged in greater amounts of illegal subsistence strategies and experienced higher levels of sexual victimization, both of which were positively linked to self-mutilation (Table 3 ).

\section{Discussion}

We set out to answer two research questions: Do certain stigmatized statuses exacerbate the risk of self-mutilation beyond the social circumstance of being homeless? Are the correlates of self-mutilation among homeless young adults different than those found among general population or clinical samples? Although homeless young people experience numerous stressors due to daily survival issues, we expected that additional status strains such as gender and sexual orientation, which are often

Table 2. Mean comparisons of males vs. females and GLB vs. heterosexual on all study variables.

\begin{tabular}{|c|c|c|c|c|c|c|c|c|c|c|}
\hline & \multicolumn{2}{|c|}{ Male } & \multicolumn{2}{|c|}{ Female } & \multirow{2}{*}{$\begin{array}{c}\text { Means } \\
\text { difference }^{a}\end{array}$} & \multicolumn{2}{|c|}{ GLB } & \multicolumn{2}{|c|}{ Heterosexual } & \multirow{2}{*}{$\begin{array}{c}\text { Means } \\
\text { difference }^{b}\end{array}$} \\
\hline & Mean & S.D. & Mean & S.D. & & Mean & S.D. & Mean & S.D. & \\
\hline Self-mutilation (0-13) & 2.25 & 2.83 & 2.80 & 3.32 & -1.15 & 4.46 & 3.68 & 1.96 & 2.64 & $4.58 * * *$ \\
\hline Sexual abuse $(0-7)$ & 1.21 & 1.96 & 2.26 & 2.37 & $-3.18^{* *}$ & 3.15 & 2.72 & 1.25 & 1.86 & $4.81^{* * *}$ \\
\hline Neglect (0-6) & 1.58 & 1.74 & 2.04 & 1.83 & -1.65 & 2.18 & 2.09 & 1.65 & 1.69 & 1.57 \\
\hline Number of time run (1-6) & 2.01 & 1.41 & 2.61 & 1.67 & $-2.53 *$ & 2.82 & 1.85 & 2.11 & 1.43 & $2.45^{*}$ \\
\hline PTSD (0-73) & 34.95 & 23.23 & 35.82 & 23.54 & -.23 & 49.51 & 18.47 & 31.52 & 23.02 & $4.27^{* * *}$ \\
\hline Substance use (0-3) & 2.15 & .96 & 1.78 & .98 & $2.44^{*}$ & 2.00 & 1.03 & 2.00 & .97 & .00 \\
\hline Sexual victimization $(0-4)$ & .48 & 1.04 & 1.49 & 1.52 & $-5.12^{* * *}$ & 1.83 & 1.69 & .64 & 1.12 & $4.99 * * *$ \\
\hline Illegal subsistence strategies (0-12) & 3.78 & 3.54 & 3.37 & 3.50 & .73 & 4.82 & 3.70 & 3.33 & 3.43 & $2.21^{*}$ \\
\hline
\end{tabular}

$* * * *<.001 ; * * p<.01 ; * p<.05$

${ }^{a}$ Difference between male and female

${ }^{\mathrm{b}}$ Difference between GLB and heterosexual ( $t$-test used) 


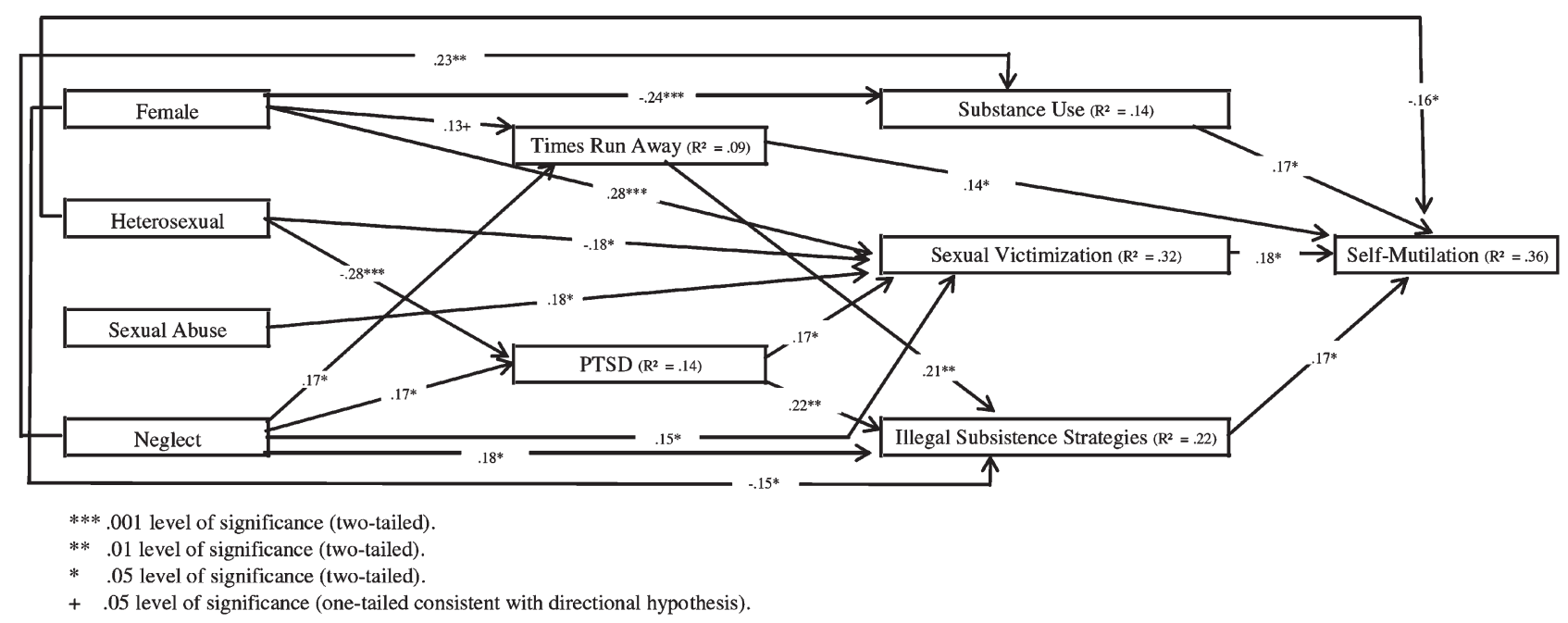

Figure 1. Self-mutilation path model (standardized coefficients shown) $(n=172)$.

Table 3. Full model results (standardized).

\begin{tabular}{|c|c|c|c|c|c|c|}
\hline \multirow[b]{2}{*}{ Variables } & \multicolumn{2}{|l|}{$\begin{array}{l}\text { Direct } \\
\text { effect }\end{array}$} & \multicolumn{2}{|c|}{$\begin{array}{l}\text { Total indirect } \\
\text { effect }\end{array}$} & \multicolumn{2}{|l|}{$\begin{array}{l}\text { Total } \\
\text { effect }\end{array}$} \\
\hline & Estimate & S.E. & Estimate & S.E. & Estimate & S.E. \\
\hline Female & -.022 & .070 & -.003 & .045 & -.025 & .071 \\
\hline Heterosexual & $-.156^{*}$ & .069 & $-.103^{*}$ & .040 & $-.259 * * *$ & .072 \\
\hline Sexual abuse & .043 & .071 & $.099^{*}$ & .038 & $.143+$ & .076 \\
\hline Neglect & .070 & .068 & $.157^{* * *}$ & .039 & $.228^{* *}$ & .070 \\
\hline Times run away & $.144^{*}$ & .067 & .046 & .031 & $.190^{* *}$ & .069 \\
\hline PTSD & 109 & .069 & $.075^{*}$ & .031 & $.185^{* *}$ & .071 \\
\hline Substance use & $.166^{*}$ & .072 & & & & \\
\hline Sexual victimization & $.182^{*}$ & .076 & & & & \\
\hline $\begin{array}{l}\text { Illegal subsistence } \\
\text { strategies }\end{array}$ & $.169^{*}$ & .078 & & & & \\
\hline
\end{tabular}

associated with poorer health outcomes (Biernbaum and Ruscio, 2004; Van Voorhees et al., 2008), would further increase the risk for self injury.

For our first research question, our results reveal that GLB young adults experience significantly more self-mutilation compared to their heterosexual counterparts, a finding that is consistent with the literature (Skegg et al., 2003; Whitlock et al., 2006) and a social stress framework. Sexual orientation is a marker of social placement (Aneshensel et al., 1991) that affects the way in which lived reality is experienced, impacting both the stressors encountered such as hate crimes, discrimination, and frequent expulsion from home (Cochran et al., 2002; Herek et al., 2002) as well as the mechanisms mobilized to cope with stress. Although we find that females self-mutilate more often than males, this difference was not significant and is inconsistent with some of the previous research on self-mutilation (Lipschitz et al., 1999; Ross and Heath, 2002; Zlotnick et al., 1999). Possible reasons for the discrepancy include different populations, age groups, and measures employed across studies. In addition, this finding does not fit the general pattern associated with a social stress framework. Women are expected to be exposed to higher levels of stressors than men and thus experience poorer mental health outcomes; however, our data do not support this contention. Thus the answer to our first question is that the stigmatized status of being GLB exacerbates the risk of self-mutilation beyond the social circumstance of being homeless whereas gender does not.

In response to our second question, we found that correlates of self-mutilation in general population samples are similar to those among homeless young adults. Our findings are consistent with the self-mutilation literature on both community and inpatient populations: sexual abuse and neglect are significant correlates of self-mutilation (Briere and Gil, 1998; Gladstone et al., 2004; van der Kolk et al., 1991; Lipschitz et al., 1999). Similarly, we find that PTSD, substance use, sexual victimization, and illegal subsistence strategies are all associated with self-mutilation, which is consistent with prior research comprised of clinical and/or high-risk samples (Gladstone et al., 2004; Swift et al., 1996; Tyler et al., 2003; Zlotnick et al., 1999).

According to a social stress framework, stressors tend to vary according to one's social location and thus their impact on mental health outcomes are likely to differ across groups; our results support this for GLBs but not for females. Our findings indicate that the social circumstance of being homeless heightens an individual's risk of experiencing mental health problems. For example, because homeless individuals are faced with the stressors associated with their disadvantaged circumstance, many of them engage in destructive behaviors including self-mutilation because they likely lack adaptive alternatives. The daily struggles that they experience such as having to secure a place to stay for the night and finding food makes the situation of homelessness a unique social circumstance. Thus, homeless males and females experience similar levels of stress due to meeting their daily survival needs over and above those associated with gender. Therefore, rates of self-mutilation for homeless males and females are similar. In contrast, because sexual minorities are stigmatized (D'Augelli, 1998) due to their social status and experience numerous negative outcomes including victimization ( $\mathrm{D}^{\prime}$ Augelli et al., 2002), they are at risk for poor mental health outcomes (Cochran et al., 2003; Ueno, 2005). Overall, it appears that among these homeless individuals, the social stress framework provides a plausible rationale for why GLBs self-mutilate more frequently than heterosexuals but does not account for the lack of the differences in self-mutilation rates for males and females.

Our findings have implications for a social stress framework which is generally applied to wider population samples. We suspect that our gender related results diverge from many general population findings because we are working with a sample experiencing a unique social circumstance and therefore does not fit the pattern usually associated with a social stress framework. This suggests that the effects of stress on outcomes may be context dependent. Among youth without reliable housing, gender expectations and interactions with others are likely to be less salient than survival and thus gender differences do not emerge. 
On the other hand, sexual orientation matters as GLB homeless youth are stigmatized not only for being homeless but for being sexual minorities, which exacerbates the risk for self-mutilation.

Some limitations should be noted. First, all data are based on self-reports. Despite this, participants were informed that their responses would be confidential and the interviewers were already known and trusted by many of the young people so it is less likely that the respondents would be motivated to bias their responses. Another limitation is the retrospective nature of many of the measures which may have resulted in some overor underreporting. Third, this study was cross-sectional; therefore, we cannot make inferences about causality. However, because we had information on the respondent's age for important events (i.e., sexual abuse, running away, and self-mutilation), we were able to determine that the risk factors occurred prior to self-mutilation, giving credence to the ordering of variables that we hypothesized as leading to self-mutilation. Fourth, the number of parameters we estimated is rather large given our smaller sample size. Ideally, to more fully examine differences by sexual orientation, a larger sample would be required. Finally, because we conducted multiple t-tests, there is the possibility that we may be capitalizing on chance for the mean comparisons.

Despite these limitations, this paper also has numerous strengths and contributes to our understanding of self-mutilation within a social stress context. According to a social stress framework, the location of individuals within the social system influences their chances of encountering stressors which, in turn, increases their likelihood of becoming emotionally distraught (Aneshensel, 1992). The stressors associated with disadvantaged status create pressures toward harmful behavior, including selfmutilation. Our study indicates that sexual orientation is a status strain that exacerbates the risk for self-mutilation among homeless individuals and thus GLBs are at higher risk for this damaging behavior. In contrast, our results show that homelessness is a unique social circumstance and that gender does not add to homeless youths' already increased levels of stress. Due to their lack of resources and support, numerous homeless individuals including both males and females may cope with distal and proximal stressors in maladaptive ways including self-mutilation. Additionally, because many homeless youth mistrust mainstream institutions (Auerswald \& Eyre, 2002), they are less likely to receive help. Consequently the social circumstance of homelessness is paramount and thus gender does not contribute additional risk among this population when it comes to self-mutilation.

Our findings have several implications for service providers. Although homeless young adults engage in high rates of selfmutilation, GLB individuals are especially vulnerable given the multiple stressors that they face, such as discrimination, isolation, and conflicts with parents over their sexual orientation prior to leaving home (Cochran et al., 2002). To encourage GLB youth to seek services, shelters and agencies should explicitly advertise through posters or flyers that sexual minority individuals are welcome and tailor programs to be sensitive to sexual orientation. Hiring GLB staff members who are open about their sexual orientation may also increase the likelihood that these youth will participate in programs aimed at reducing self-mutilation. Our findings also indicate that early stressors such as sexual abuse and/or neglect lead to substance use, illegal subsistence strategies, and sexual victimization which, in turn, increase the risk for self injury. Because child abuse histories have a lasting impact on the mental health and behaviors of homeless youth, it is important for case workers and service providers to address these issues through programs aimed at helping these youth to constructively cope with their negative emotions.
There are several avenues for future research. Because there is a paucity of research that uses a social stress framework to examine the effect of social location on self-mutilation within this population, we have little with which to compare our results. As such, future research should build upon our findings and examine macro-level processes using other nontraditional populations such as foster care or incarcerated youth. Also, given that sexual orientation was found to exacerbate the risk for selfmutilation beyond the social circumstance of homelessness, additional studies are needed to see whether this finding can be replicated, which may have important implications for the social stress framework. Finally, future research should examine whether personal resources such as self-esteem or self-efficacy mediate the link between stress and other related mental health outcomes among similar high-risk populations.

\section{Acknowledgments}

This research was supported by the National Institute of Mental Health (MH064897). Dr. Kimberly A. Tyler, PI. A special thanks to Christina Falci and Julia McQuillan for their helpful comments on an earlier version of this manuscript. We thank the Senior Editor and the three anonymous reviewers for Social Science $\mathcal{E}$ Medicine for their thorough comments on previous drafts of this manuscript.

\section{References}

Aneshensel, 19924 C. S. Aneshensel, Social stress: theory and research, Annual Review of Sociology 18 (1992), pp. 15-38.

Aneshensel, $1999 \varangle$ C. S. Aneshensel, Outcomes of the stress process. In: A. V. Horwitz and T. L. Scheid, eds., A handbook for the study of mental health: Social contexts, theories, and systems, Cambridge University Press, New York (1999), pp. 211-227.

Aneshensel et al., 1991 C. S. Aneshensel, C. M. Rutter, and P. A. Lachenbruch, Social structure, stress, and mental health: competing conceptual and analytic models, American Sociological Review 56 (1991), pp. 166-178.

Auerswald and Eyre, 2002 C. Auerswald and S. L. Eyre, Youth homelessness in San Francisco: a life cycle approach, Social Science $\mathcal{E}$ Medicine 54 (2002), pp. 1497-1512.

Biernbaum and Ruscio, 2004 M. A. Biernbaum and M. Ruscio, Differences between matched heterosexual and non-heterosexual college students on defense mechanisms and psychopathological symptoms, Journal of Homosexuality 48 (2004), pp. 125-141.

Briere, 19974 J. Briere, Psychological assessment of adult posttraumatic states, American Psychological Association, Washington D. C. (1997).

Briere and Gil, 19984 J. Briere and E. Gil, Self-mutilation in clinical and general population samples: prevalence, correlates, and functions, American Journal of Orthopsychiatry 68 (1998), pp. 609-620.

Chen et al., $2004 \varangle$ X. Chen, K. A. Tyler, L. B. Whitbeck, and D. R. Hoyt, Early sexual abuse, street adversity, and drug use among female homeless and runaway adolescents in the Midwest, Journal of Drug Issues 34 (2004), pp. 1-21.

Clatts and Davis, 19994 M. C. Clatts and W. R. Davis, A demographic and behavioral profile of homeless youth in New York city: implications for AIDS outreach and prevention, Medical Anthropology Quarterly 13 (1999), pp. 365-374.

Cochran et al., 20024 B. N. Cochran, A. J. Stewart, J. A. Ginzler, and A. M. Cauce, Challenges faced by homeless sexual minorities: comparison of gay, lesbian, bisexual, and transgender homeless adolescents with their heterosexual counterparts, American Journal of Public Health 92 (2002), pp. 773-777.

Cochran et al., $2003<$ S. D. Cochran, J. Greer Sullivan, and V. M. Mays, Prevalence of mental disorders, psychological distress, and mental health services use among lesbian, gay, and bisexual adults in the United States, Journal of Consulting and Clinical Psychology 71 (2003), pp. 53-61. 
D'Augelli, 1998 A. R. D'Augelli, Developmental implications of victimization of lesbian, gay, and bisexual youths. In: G. M. Herek, Editor, Stigma and sexual orientation: Understanding prejudice against lesbians, gay men, and bisexuals, Sage Publications, Thousand Oaks, CA (1998), pp. 187-210.

D'Augelli et al., 20024 A. R. D'Augelli, N. W. Pilkington, and S. L. Hershberger, Incidence and mental health impact of sexual orientation victimization of lesbian, gay, and bisexual youths in high school, School Psychology Quarterly 17 (2002), pp. 148-167.

Demakakos et al., $2008<$ P. Demakakos, J. Nazroo, E. Breeze, and M. Marmot, Socioeconomic status and health: the role of subjective social status, Social Science \& Medicine 67 (2008), pp. 330-340.

Favazza, 1998 A. R. Favazza, The coming of age of self-mutilation, The Journal of Nervous and Mental Disease 186 (1998), pp. 259-268.

Favazza and Conterio, $1989 \varangle$ A. R. Favazza and K. Conterio, Female habitual self-mutilators, Acta Psychiatrica Scandinavica 79 (1989), pp. 283-289.

Gladstone et al., $2004 \varangle$ G. L. Gladstone, G. B. Parker, P. B. Mitchell, G. S. Malhi, K. Wilhelm, and M. P. Austin, Implications of childhood trauma for depressed women: an analysis of pathways from childhood sexual abuse to deliberate self-harm and revictimization, American Journal of Psychiatry 161 (2004), pp. 1417-1425.

Gratz, 2001 K. L. Gratz, Measurement of deliberate self-harm: preliminary data on the deliberate self-harm inventory, Journal of Psychopathology and Behavioral Assessment 23 (2001), pp. 253-263.

Gratz et al., 20024 K. L. Gratz, S. D. Conrad, and L. Roemer, Risk factors for deliberate self-harm among college students, American Journal of Orthopsychiatry 72 (2002), pp. 128-140.

Herek et al., 20024 G. M. Herek, J. C. Cogan, and J. R. Gillis, Victim experiences in hate crimes based on sexual orientation, Journal of Social Issues 58 (2002), pp. 319-339.

Honjo et al., $2006 \triangleleft$ K. Honjo, A. Tsutsumi, I. Kawachi, and N. Kawakami, What accounts for the relationship between social class and smoking cessation? Results of a path analysis, Social Science $\mathcal{E}$ Medicine 62 (2006), pp. 317-328.

Horowitz et al., 19794 M. J. Horowitz, N. Wilner, and W. Alvarez, Impact of event scale: a measure of subjective stress, Psychosomatic Medicine 41 (1979), pp. 209-218.

Kipke et al., 1995 M. D. Kipke, S. O'Connor, R. Palmer, and R. G. MacKenzie, Street youth in Los Angeles: profile of a group at high risk for HIV, Archives of Pediatric and Adolescent Medicine 149 (1995), pp. 513-519.

van der Kolk et al., $1991<$ B. A. van der Kolk, J. C. Perry, and J. L. Herman, Childhood origins of self-destructive behavior, American Journal of Psychiatry 148 (1991), pp. 1665-1671.

Kubzansky et al., 1998 L. D. Kubzansky, L. F. Berkman, T. A. Glass, and T. E. Seeman, Is educational attainment associated with shared determinants of health in the elderly? Findings from the MacArthur studies of successful aging, Psychosomatic Medicine $\mathbf{6 0}$ (1998), pp. 578-585.

Lipschitz et al., 19994 D. S. Lipschitz, R. K. Winegar, A. L. Nicolaou, E. Hartnick, M. Wolfson, and S. M. Southwick, Perceived abuse and neglect as risk factors for suicidal behavior in adolescent inpatients, The Journal of Nervous and Mental Disease 187 (1999), pp. 32-39.

Muthén and Muthén, 1998-2007 \ L. K. Muthén and B. O. Muthén, Mplus user's guide (4th ed. ), Muthén and Muthén, Los Angeles, CA (1998-2007).

Nock and Prinstein, 20044 M. K. Nock and M. J. Prinstein, A functional approach to the assessment of self-mutilative behavior, Journal of Consulting and Clinical Psychology 72 (2004), pp. 885-890.

Nock et al., $2008-$ M. K. Nock, M. M. Wedig, I. B. Janis, and T. L. Deliberto, Self-injurious thoughts and behaviors. In: J. Hunsley and E. Mash, eds., A guide to assessments that work, Oxford University Press, New York (2008), pp. 158-177.

Pearlin, 19994 L. Pearlin, Stress and mental health: a conceptual overview. In: A. V. Horwitz and T. L. Scheid, eds., A handbook for the study of mental health: Social contexts, theories, and systems, Cambridge University Press, New York (1999), pp. 161-175.
Ross and Heath, $2002 \varangle$ S. Ross and N. L. Heath, A study of the frequency of self-mutilation in a community sample of adolescents, Journal of Youth and Adolescence 31 (2002), pp. 67-77.

Skegg et al., 2003 K. Skegg, S. Nada-Raja, N. Dickson, C. Paul, and S. Williams, Sexual orientation and self-harm in men and women, American Journal of Psychiatry 160 (2003), pp. 541-546.

Slesnick and Prestopnik, $2005 \varangle$ N. Slesnick and J. Prestopnik, Dual and multiple diagnosis among substance using runaway youth, The American Journal of Drug and Alcohol Abuse 1 (2005), pp. 179-201.

Straus et al., $1998 \triangleleft$ M. A. Straus, S. L. Hamby, D. Finkelhor, D. W. Moore, and D. Runyan, Identification of child maltreatment with the parent-child conflict tactics scales: development and psychometric data for a national sample of American parents, Child Abuse and Neglect 22 (1998), pp. 249-270.

Suyemoto, $1998<$ K. L. Suyemoto, The functions of self-mutilation, Clinical Psychology Review 18 (1998), pp. 531-554.

Swift et al., $1996 \&$ W. Swift, J. Copeland, and W. Hall, Characteristics of women with alcohol and other drug problems: findings of an Australian national survey, Addiction 91 (1996), pp. 1141-1150.

Tyler, $2008 \triangleleft \mathrm{K}$. A. Tyler, A comparison of risk factors for sexual victimization among gay, lesbian, bisexual, and heterosexual homeless young adults, Violence and Victims 23 (2008), pp. 586-602.

Tyler and Cauce, $2002 \varangle \mathrm{K}$. A. Tyler and A. M. Cauce, Perpetrators of early physical and sexual abuse among homeless and runaway adolescents, Child Abuse and Neglect 26 (2002), pp. 1261-1274.

Tyler et al., $2001<$ K. A. Tyler, D. R. Hoyt, L. B. Whitbeck, and A. M. Cauce, The impact of childhood sexual abuse on later sexual victimization among runaway youth, Journal of Research on Adolescence 11 (2001), pp. 151-176.

Tyler et al., 2003 K. A. Tyler, L. B. Whitbeck, D. R. Hoyt, and K. D. Johnson, Self-mutilation and homeless youth: the role of family abuse, street experiences, and mental disorders, Journal of Research on Adolescence 13 (2003), pp. 457-474.

Ueno, 20054 K. Ueno, Sexual orientation and psychological distress in adolescence: an examination of interpersonal stressors and social support processes, Social Psychology Quarterly 68 (2005), pp. 258-277.

Van Voorhees et al., $2008 \triangleleft$ B. W. Van Voorhees, D. Paunesku, S. A. Kuwabara, A. Basu, J. Gollan, and B. L. Hankin et al., Protective and vulnerability factors predicting new-onset depressive episode in a representative of U. S. adolescents, Journal of Adolescent Health 42 (2008), pp. 605-616.

Wheaton, $1999 \varangle \mathrm{B}$. Wheaton, The nature of stressors. In: A. V. Horwitz and T. L. Scheid, eds., A handbook for the study of mental health: Social contexts, theories, and systems, Cambridge University Press, New York (1999), pp. 176-197.

Whitbeck et al., $2000<$ L. B. Whitbeck, D. R. Hoyt, and W. N. Bao, Depressive symptoms and co-occurring depressive symptoms, substance abuse, and conduct problems among runaway and homeless adolescents, Child Development 71 (2000), pp. 721-732.

Whitbeck and Simons, $1990<$ L. B. Whitbeck and R. L. Simons, Life on the streets: the victimization of runaway and homeless adolescents, Youth and Society 22 (1990), pp. 108-125.

Whitlock et al., 20064 J. Whitlock, J. Eckenrode, and D. Silverman, Self-injurious behaviors in a college population, Pediatrics 117 (2006), pp. 1939-1948.

Wright, 1991 J. D. Wright, Health and the homeless teenager: evidence from the national health care for the homeless program, Journal of Health and Social Policy 2 (1991), pp. 15-35.

Wright et al., $1995<$ J. D. Wright, T. L. Allen, and J. A. Devine, Tracking non-traditional populations in longitudinal studies, Evaluation and Program Planning 18 (1995), pp. 267-277.

Zlotnick et al., 1999 C. Zlotnick, J. I. Mattia, and M. Zimmerman, Clinical correlates of self-mutilation in a sample of general psychiatric patients, The Journal of Nervous and Mental Disease 187 (1999), pp. 296-301. 